\title{
Observations of some epidemiological and reproductive factors in women with Breast cancer at the Niger Delta University Teaching hospital, Okolobiri, Bayelsa State, Nigeria.
}

\author{
Alagoa, Paingha $\mathbf{J}^{1}$, Dakpokpo Oshoke ${ }^{2}$, Mukoro Duke George ${ }^{3}$ \\ B.Med.Sc, MBBS, FMCS, FICS; $\quad$ B.SC MBBS; B.Sc,MBBS, MCS ${ }^{0}$,HSE, ATLS, DTM\&H (Liverpool). \\ ${ }^{1,2,3}$ Department of Surgery, Niger Delta University Teaching Hospital, Okolobiri, Bayelsa State, Nigeria.
}

\begin{abstract}
Background: Breast cancer is an important cause of morbidity and mortality in women. Certain reproductive and epidemiologic factors are associated with this disease. This study aims at documenting some epidemiological and reproductive characteristics of women diagnosed with breast cancer.

Study Design: A retrospective study.

Place and Duration of Study: All women who had had histological diagnosis of breast cancer at the Niger Delta University teaching hospital, Okolobiri between January 2010 and December, 2012 were retrospectively studied.

Method: Relevant information was obtained from patients' case notes and admissions and discharge register. Information obtained was recorded on a proforma.

Results: The mean age of women with breast cancer at diagnosis was $44.2 \pm 11.6$ years. The youngest was 24 years and the oldest 70 years. The peak age of incidence was between 31-40 years. Mean parity of women was $4.7 \pm 2.5$ years while the mean age of menarche was $15.2 \pm 0.9$ years. $15 \%$ of the women had a positive family history. $72.5 \%$ had cancer affecting the left breast only, while $22.5 \%$ affected only the right and $5.0 \%$ were bilateral.

Conclusion: Breast cancer appears to occur at a younger age in this study.

Keywords: breast cancer, age, parity, menarche.
\end{abstract}

\section{Introduction}

Breast cancer is a common cause of morbidity and mortality in women ${ }^{1,2}$. Globally, it accounts for about $31 \%$ of all cancers in women ${ }^{1}$. In Nigeria and other countries, breast cancer is the leading cause of cancer in women ${ }^{3,4,5}$. Its incidence appears to be rising

It must be noted that the actual cause of breast cancer is not known. However, there are risk factors that have been suggested following epidemiological studies. Some of these risk factors include age, sex, family history, diet, previous breast cancer and other reproductive factors like menarche, parity and age at first term pregnancy.

There is however a paucity of studies in Nigeria on the significance of these factors. In this part of the country, there are even fewer. Some persons have continued to make references to studies done in other parts of the world particularly among Caucasians. Evidence however suggests that there are significant differences between breast cancer among Caucasians and Africans ${ }^{6}$. We therefore undertook this study to document some of these epidemiologic and reproductive factors in women with breast cancer.

\section{Materials and Methods}

This study was conducted at the Niger Delta University teaching hospital, Okolobiri which is a newly established tertiary hospital situated in a semi-urban community in the Niger Delta region of Nigeria. Clearance was obtained from the hospital's Ethical committee to undertake this study. All patients diagnosed with breast cancer between January, 2010 and December, 2013 at the hospital were retrospectively studied. Patients whose hospital records were not complete were excluded from the study.

Information and other data on the patients were retrieved from patients' case notes and the ward admission and discharge registers. Such information was recorded on a pro forma and data was analysed using the IBM SPSS version 20.The results are presented in tables and charts.

\section{Results}

A total of 43 patients were diagnosed with breast cancer during the period. Three patients were however excluded because their hospital records were lacking on the parameters to be studied. Forty patients were therefore included in the study.

The mean age of the women with breast cancer was $44.2 \pm 11.6$ years. The youngest woman was 24 years while the oldest was 70 years. The peak incidence of $42.5 \%$ was in those aged between 31-40 years. The 
mean age of menarche was $15.2 \pm 0.9$ years. The youngest was 14 years at menarche while 18 years was the oldest age at menarche. The mean parity of the women was $4.7 \pm 2.5$. Six women were nulliparous. The highest parity was 9. Also, associated with this was breast feeding. All women with children $34(85.0 \%)$ breast fed for at least one year, the only women who did not breast feed were those who were nulliparous $6(15.0 \%)$.

Six $(15.5 \%)$ patients had a family history of breast cancer in a first degree relative while $34(85.0 \%)$ did not. There bilateral breast cancer in $2(5.0 \%)$ women. The least breast alone was affected in $29(72.5 \%)$ of women while the right breast alone was affected in $9(22.5 \%)$.

Table 1: Age distribution of women with breast cancer

\begin{tabular}{|c|c|c|}
\hline Age (years) & Number of women & Percentage \\
\hline $21-30$ & 2 & $5.0 \%$ \\
\hline $31-40$ & 17 & $42.5 \%$ \\
\hline $41-50$ & 9 & $22.5 \%$ \\
\hline $51-60$ & 9 & $22.5 \%$ \\
\hline $61-70$ & 3 & $7.5 \%$ \\
\hline TOTAL & 40 & $100.0 \%$ \\
\hline
\end{tabular}

Table 2: Shows cancer affected breasts

\begin{tabular}{|l|c|c|}
\hline Affected breast & Number of women & Percentage \\
\hline Bilateral & 2 & $5.0 \%$ \\
\hline Right breast only & 9 & $22.5 \%$ \\
\hline Left breast only & 29 & $72.5 \%$ \\
\hline TOTAL & 40 & $100.0 \%$ \\
\hline
\end{tabular}

Figure 1: Age distribution of women with breast cancer

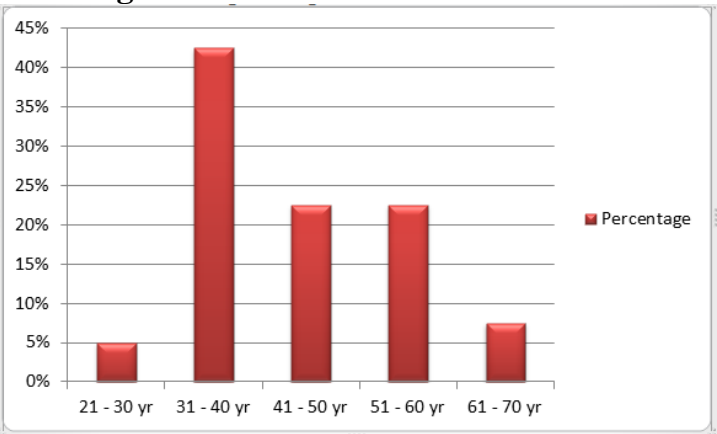

Figure 2: Shows breasts affectation pattern

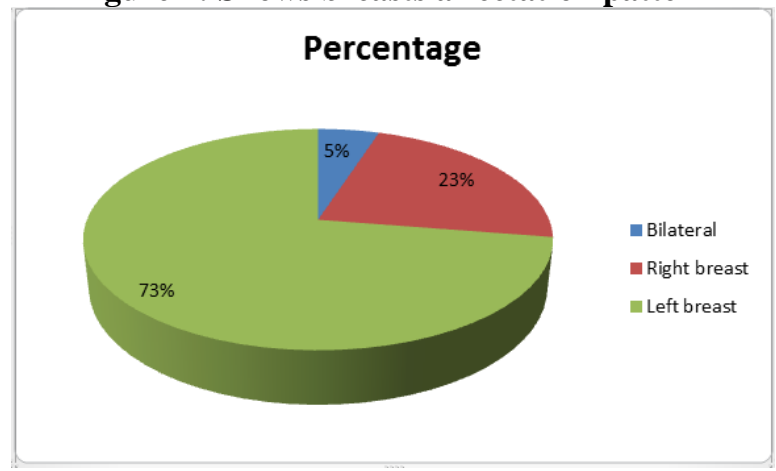

\section{Discussion}

Results from our study show that the peak incidence of breast cancer was between 31 to 40 years. The mean age of the disease was 44.2 years. This is similar to but lower than results from studies from other parts of Nigeria $^{7,8,9}$. The mean age of diagnosis at Ibadan was 51.1 years, while that in Abuja, Nigeria was 49.9 years ${ }^{10}$. These reports are slightly higher than what we observed in our study. The peak age of incidence is said to be 1015 years earlier in Nigerian women as compared with Caucasians. Also about 70-80\% of these occur in premenopausal women. This is similar African- Americans who also have a high premenopausal breast cancer rates. This has been linked to the high levels of estrogen in black women ${ }^{11,12}$.

Parity and breast feeding are known to have a complex relationship with breast cancer. Parity and breast feeding have been found to be protective against breast cancer in Nigerian women ${ }^{13}$. In our study, the mean parity was 4.7 years. It is difficult to conclusively make inferences from this since this study was not a 
case-control study. Also, $85 \%$ of our subjects breast fed their children for over 12 months. This is contrary to the generally accepted fact that breast feeding protects against breast cancer. It has been shown however that breast feeding decreased breast cancer risk by $7 \%$ for every 12 months of breast feeding ${ }^{13}$.

Menarche is also an important reproductive risk factor in breast cancer. Our study revealed a menarche of 15.2 years in women with breast cancer. This agrees with findings that menarche of less than 17 years increases the risk of breast cancer ${ }^{13,14}$. It is an established fact that delay of menarche of 2 years corresponds with $7 \%$ reduction in Nigerian women at risk for breast cancer ${ }^{14}$. This is in keeping with an international multicentre study which reported a $10 \%$ decrease in breast cancer risk.

We also found unilateral breast cancer to be more common in the left breast than the right. This appears to be the general picture. Tulinius and his colleagues in Europe also found left breast cancer to be $13 \%$ in excess to that on the right side ${ }^{15}$.

\section{Conclusion}

Breast cancer appears to have a peak incidence among young women in this part of Nigeria.

\section{References}

[1]. Anderson BO, Shyyan R, Eniu A, Smith RA, Yip CH, Bese NS, Chow LW, Masood S, Ramsey SD, Carlson RW: 2006. Breast cancer in limited-resource countries: An overview of the Breast Health Initiative 2005 Guidelines. Breast J, 12 (Suppl 1):S3-15.

[2]. Jamal A, Siegel R, Ward E, Murray T, Xu J, Smigal C, Thun MJ: Cancer statistics 2006. CA: A Cancer J Clin 2005; 56(2): 106130.

[3]. Parkin DM, Bray F, Ferlay J, Pisani P. Global cancer stistics. 2002. CA Cancer J Clin. 2005; 55: 74-108.

[4]. Adebamowo CA, Ajayi OO. Breast cancer in Nigeria. West Afr J Med. 2000; 19: 179-191.

[5]. American Cancer Society: Breast Cancer Facts \& Figures 2005 - 2006. American Cancer Society Inc. Atlanta 2005.

[6]. Mayberry RM, Stoddard- Wright C. Breast cancer risk factors among black and white women: Similarities and differences. American Journal of Epidemiology. 1993; 136 (12): 1445-1456.

[7]. Anyanwu SN. Breast cancer in Eastern Nigeria: A ten year review. W Afr J Med. 2000; 19(2): 120-125.

[8]. Okobia MN, Osime U. Clinicopathological study of carcinoma of the breast in Benin City. AJRH. 2001; 5(2): 56-62.

[9]. Ihekwaba FN. Breast cancer in Nigerian women. Br J Surg. 1992; 79: 771-775.

[10]. Jedy- Agba E, Curado MP, Ogunbiyi O, Oga E, Fabowale Igbinoba F, Osubor G, Otu T, Kumai H, Koechlin A, Osinubi P, Dakum P, Blattner W, Adebamowo CA. Cancer Epidemiol. 2012; 36(5): e271-278.

[11]. Danforth DN Jr. Disparities in breast cancer outcomes between Caucasians and African American women: a model for describing the relationship of biological and non-biological factors. Breast Cancer Res. 2013; 15(3): 208.

[12]. Marsh EE, Shaw ND, Klingman KM et al. Estrogen levels are higher across the menstrual cycle in African- American women compared with Caucasian women. Journal of Clinical Endocrinology \& Metabolism. 2011; 96(10): 3199-3206.

[13]. Huo D, Adebamowo CA, Ogundiran TO, Akang EE, Campbell O, Adenipekun A, Cummings S, Fackenthal J, Ademuyiwa F, Ahasan H, Olopade OI. Parity and breast feeding are protective against breast cancer in Nigerian women. Br J Cancer. 2008; 98 : 992-996.

[14]. Adebamowo CA, Ogundiran TO, Adenipekun AA, Oyesegu RA, Campbell OB, Akang EU, Rotimi CN, Olopade OI. Obessity and height in urban Nigerian women with breast cancer. Ann Epidemiol. 2003; 13: 455-461.

[15]. Tulinius H, Sigvaldason H, Olafsdottir G. Left and right sided breast cancer. Pathol Res Pract. 1990; 186(1): 92-94. 